\title{
MJN \\ THE ANTECEDENTS OF JOB PERFORMANCE AMONG \\ NURSES WORKING IN MALAYSIAN GOVERNMENT HOSPITALS, AGE BEING A MODERATOR
}

\author{
Pavitira Manogaran*, Rajendran Muthuveloo \\ University Science Malaysia, Pulau Pinang, Malaysia \\ *Corresponding Author's Email:pavitira_94@hotmail.com
}

\begin{abstract}
Purpose: The aim of this study was to investigate the relationship between workplace mindfulness, cognition, emotion, behaviour and psychology on job performance. In addition, age was tested as the moderating factor on the relationship between workplace mindfulness, cognition, emotion, behaviour and psychology on job performance. Method: The research was conducted on nurses working in Malaysian government hospitals among 127 respondents were chosen. Data was collected from the respondents using a structured questionnaire. The data were analysed with factor analysis, reliability test and multiple regression analysis. Results: Results indicated that only workplace mindfulness, cognition and behaviour had a positive significant influence on job performance. Age moderated the relationship between the cognition, behaviour and psychology positively and significantly on job performance. Contribution: The Malaysian government hospital management is suggested to focus on these three factors in order to overcome job performance issue among nurses.
\end{abstract}

Keywords: Job Performance, Nurses, Workplace Mindfulness, Cognition, Emotion, Behaviour, Psychology, Age

\section{INTRODUCTION}

Job performance has been declining over the past years in the Malaysian health care industry among nurses, due to several reasons. Shortage of nurses has been identified to massively contribute to low job performance, and the shortage was identified to be due to two major reasons. From the year 2005 to 2010, ten thousand nursing students graduated yearly. When the announcement regarding the entry requirement was made in August 2010 by the Malaysian Nursing Board, the yearly number of nursing graduates dropped to less than three thousand students. The entry requirement increased from three credits to five credits, and the National Higher Education Fund Corporation (PTPTN) decreased their loans for nursing students (Ismail, 2017).

According to the World Health Organization (WHO), the ratio of nurses to population should be
1:200, however, in Malaysia the ratio is 1:300; and ratio of nurses to doctors should be 1:2.5, however in Malaysia, the ratio is 1:2.10; indicating a huge shortage of nurses. So, the current nurses' job is extremely tough as they manage more patients, which subsequently affects their job performance (Goh, 2017).

To achieve World Health Organization (WHO) goal with respect to nurse population ratio must be achieved in order to provide excellent service to patients (Ling, 2015). Malaysia's former Chief Nurse, Bibi Florina Abdullah, referred the world today as an "oyster" for nurses due to limited nurses in developing countries with an ageing population (Augustin, 2017).

Malaysian Mental Health Association Deputy President Datuk Dr Andrew Mohanraj said, that Malaysian workforce started inheriting workplacerelated depression, and it could be Malaysia's biggest challenge as it is not easy to identify the problems due to 
hidden symptoms (Muthiah, 2017).

According to Dr. Ahmat Fakrudin, most nurses in government hospitals were overworked due to the shortage of nurses which makes their work more challenging, causing them to quit from their profession, due to stress and health issues (Andexer, 2016).

This study aimed to address job performance issue from the view of workplace mindfulness, cognition, emotion, behaviour and psychology and if age moderates the relationship between these variables and job performance among nurses in Malaysian government hospitals. This study aimed to enhance job performance among nurses in Malaysian government hospitals.

\section{METHODOLOGY}

The research theoretical framework was formulated based on the theory called RACE (Muthuveloo \& Teoh, 2017), SWIM Strategic Management Process Model (Muthuveloo \& Teoh, 2014) and I-TOP Strategic Agility Model (Muthuveloo \& Teoh, 2013) as shown in Figure 1. The independent variables consisted of workplace mindfulness, cognition, emotion, behavior and psychology. The dependent variable was job performance and age was the moderating variable. The research gap addressed in this research was age. As previous studies found that age had a moderating effect on job performance, this research addressed age as a moderating variable to identify if it influenced the relationship between the independent variables and the dependent variable.

Independent Variable

Dependent Variable

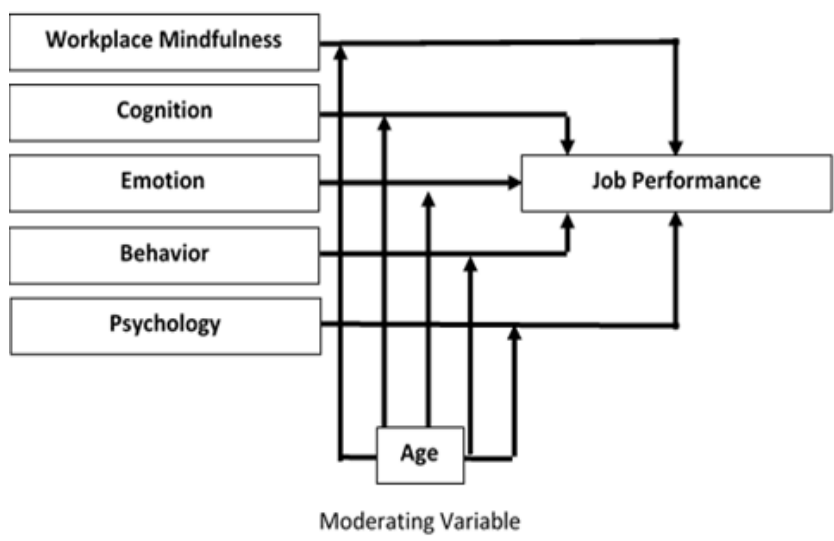

Figure 1 : Theoretical Framework
A structured questionnaire was used as the research instrument. Data were collected via the convenient sampling method through online survey. The online questionnaire was distributed through emails to the respondents whom were retrieved from the Ministry of Health website and the response of the respondents was submitted automatically. The minimum sample size needed to analyze using IBM Social Sciences (SPSS) Statistics Data Editor at 95\% confidence level is 120 . Thus, 127 respondents received was enough to run the analysis.

\section{RESULTS}

This statistical result which has been obtained from the IBM Statistical Package for the Social Sciences (SPSS) Statistics Data Editor software as below.

\section{Respondents Profile}

The profile of the respondents was based on the data analyzed in descriptive analysis from 127 respondents. In the demographic profile, the respondents were being asked about their age, gender, marital status, academic qualification, state and their nurse grade. Most of the respondents were from the age group over 41 years (58 respondents, $45.7 \%$ ) of the total respondents. The second largest was $23(18.1 \%)$ from the age group 26 to 30 years old and $21(16.5 \%)$ from the age group 31 to 35 years old; closely followed by $15(11.8 \%)$ who were ranging from 36 to 40 years old. The least number of respondents was from the age of 21 to 25 years old which 10 was $(7.9 \%)$. There were no respondents for the age group below 20 years old. The results indicated that most of the respondents were elderly nurses in the Malaysian government hospitals.

All the respondents were female 127 (100.0\%). This indicated that the females were the dominant gender in the nursing industry in the Malaysian government hospitals. The marital status of the respondents showed that $98(77.2 \%)$ of the respondents were married, whereas $28(22.0 \%)$ were single and $1(0.8 \%)$ was a divorcee. Most of the respondents were Diploma qualified which consist of $83(65.4 \%)$, followed by nurses with a bachelor's degree $35(27.6 \%)$, then a master's degree 4 (3.1\%), SPM $4(3.1 \%)$ and STPM 1 (0.8\%). No respondents had a $\mathrm{PhD} /$ Doctorate degree. The respondents were from all the thirteen states in Malaysia. Most respondents were from three states, Perak 29 
(22.8\%), Sabah 23 (18.1\%) and Sarawak 20 (15.7\%). The respondents were also asked on the nursing grade they belonged to. Majority of them were from Grade U32 54 (42.5\%), followed by Grade U29 48 (37.8\%), Grade U36 $13(10.2 \%)$ and Grade U41 12 (9.4\%).

\section{Goodness of Data}

The dependent variable being analyzed using factor analysis with regard to job performance. The independent variable being analyzed using factor analysis were workplace mindfulness, cognition, emotion, behaviour and psychology. Table 1 showed the results of factor analysis. The Kaiser-Meyer-Olkin (KMO) measuring the sampling adequacy for job performance, workplace mindfulness, cognition, emotion, behaviour and psychology indicated enough inter-correlation. The Barlett's Test of Sphericity was significant for all variables. Both KMO and Barlett's Test of Sphericity done for job performance, workplace mindfulness, cognition, emotion, behaviour and psychology indicated the dependent variable and independent variables were reliable for further analysis.

Table 1: Results of Factor Analysis

\begin{tabular}{|l|l|l|l|l|}
\hline Variables & $\begin{array}{l}\text { Kaiser- } \\
\text { Meyer-Olkin }\end{array}$ & \multicolumn{2}{|c|}{ Bartlett's Test of Sphericity } \\
\hline & (KMO) & $\begin{array}{l}\text { Approx. Chi- } \\
\text { Square }\end{array}$ & $\boldsymbol{d f}$ & Significance \\
\hline Job Performance & 0.918 & 1486.592 & 45 & 0.000 \\
\hline $\begin{array}{l}\text { Workplace } \\
\text { Mindfulness }\end{array}$ & 0.951 & 2730.364 & 105 & 0.000 \\
\hline Cognition & 0.931 & 1219.882 & 45 & 0.000 \\
\hline Emotion & 0.905 & 1211.267 & 45 & 0.000 \\
\hline Behaviour & 0.920 & 1035.306 & 45 & 0.000 \\
\hline Psychology & 0.894 & 992.728 & 45 & 0.000 \\
\hline
\end{tabular}

\section{Reliability of Instrument}

All the items have Cronbach's Alpha value more than 0.90 , hence all items were accepted and considered excellently reliable as shown in Table 2.

Table 2: Results of Reliability Analysis

\begin{tabular}{|l|c|c|c|c|}
\hline Factor & $\begin{array}{l}\text { No. of } \\
\text { Item }\end{array}$ & $\begin{array}{l}\text { No. of } \\
\text { Items Added }\end{array}$ & $\begin{array}{l}\text { No. of Items } \\
\text { Deleted }\end{array}$ & $\begin{array}{l}\text { Cronbach's } \\
\text { Alpha }\end{array}$ \\
\hline Job Performance & 10 & 0 & 0 & 0.963 \\
\hline $\begin{array}{l}\text { Workplace } \\
\text { Mindfulness }\end{array}$ & 15 & 0 & 0 & 0.976 \\
\hline Cognition & 10 & 0 & 0 & 0.955 \\
\hline Emotion & 10 & 0 & 0 & 0.950 \\
\hline Behaviour & 10 & 0 & 0 & 0.932 \\
\hline Psychology & 10 & 0 & 0 & 0.940 \\
\hline
\end{tabular}

\section{Mean of Key Research Variables}

Table 3 showed the descriptive statistics that includes the mean and standard deviation for independent variables, dependent variable and moderating variable. Both dependent and independent variable were measured in 6 Likert scale. The 6 Likert scale ranging from 1 being strongly disagree to 6 being strongly agree. The dependent variable, job performance mean value was 5.1866 and standard deviation 0.84688 . The highest mean value for independent variable was behaviour at 4.9425 (standard deviation=0.74976), cognition at 4.9339 (standard deviation $=0.80141$ ), emotion at 4.8591 (standard deviation=0.91177), psychology at 4.6976 (standard deviation $=0.88492$ ) and workplace mindfulness at 3.5407 (standard deviation=1.43359). Moderating variable mean value was 4.6929 and standard deviation 1.40584 .

Table 3: Results of Descriptive Statistics

\begin{tabular}{|l|c|c|c|}
\hline Variables & Mean & $\begin{array}{l}\text { Standard } \\
\text { Deviation }\end{array}$ & N \\
\hline Job Performance & 5.1866 & 0.84688 & 127 \\
\hline $\begin{array}{l}\text { Workplace } \\
\text { Mindfulness }\end{array}$ & 3.5407 & 1.43359 & 127 \\
\hline Cognition & 4.9339 & 0.80141 & 127 \\
\hline Emotion & 4.8591 & 0.91177 & 127 \\
\hline Behaviour & 4.9425 & 0.74976 & 127 \\
\hline Psychology & 4.6976 & 0.88492 & 127 \\
\hline Age & 4.6929 & 1.40584 & 127 \\
\hline
\end{tabular}

\section{Multiple Regression Analysis}

Multiple regression analysis was done to identify the influence of independent variables towards dependent variable and if the moderating variable impacted the relationship between the independent variables and the dependent variable predicated in the research objective and research questions.

\section{Multiple Regression Analysis without Moderator}

Multiple regression analysis was used to investigate the significance of the relationship between the dependent variable and independent variables. 
Table 4: Summary of Multiple Regression Analysis without Moderator

\begin{tabular}{|c|c|c|c|c|c|c|c|c|}
\hline $\mathbf{R}^{2}$ & Adjusted $\mathbf{R}^{2}$ & Model & Standardized beta & $t$-value & $p$-value & VIF & Sig. F Change & Durbin-Watson \\
\hline \multirow[t]{5}{*}{0.414} & \multirow[t]{5}{*}{0.389} & $\begin{array}{l}\text { Workplace } \\
\text { Mindfulness }\end{array}$ & 0.142 & 1.746 & $0.083 * *$ & 1.356 & \multirow[t]{5}{*}{0.000} & \multirow[t]{5}{*}{1.799} \\
\hline & & Cognition & 0.355 & 3.085 & $0.003^{*}$ & 2.738 & & \\
\hline & & Emotion & -0.075 & -0.648 & 0.518 & 2.802 & & \\
\hline & & Behaviour & 0.399 & 4.757 & $0.000^{*}$ & 1.451 & & \\
\hline & & Psychology & -0.012 & -0.124 & 0.902 & 2.093 & & \\
\hline
\end{tabular}

Note: *-Significant at $p<0.05$; **-Significant at $p<0.1$

Table 4 above showed the results from multiple regression analysis (MRA) tested on the model without a moderator. R-square value was 0.414 , which means $41.4 \%$ of the variation in job performance can be explained by workplace mindfulness, cognition, emotion, behaviour, and psychology. The DurbinWatson statistic was used to test the presence of serial correlation among the residuals. Durbin-Watson statistic was 1.799 which was approximately 2 indicated no serial correlation.

The results indicated that the effects of workplace mindfulness $(\beta=0.142, p<0.1)$, cognition $(\beta=0.355$, $p<0.05)$ and behaviour $(\beta=0.399, p<0.05)$ showed a positive significant influence on job performance and the effect of emotion $(\beta=-0.075, p>0.05)$ and psychology $(\beta=-0.012, p>0.05)$ showed a negative and not significant influence on job performance. As such, hypothesis H1, H2, and H4 were supported, whereas H3 and $\mathrm{H} 5$ were not supported. The VIF (variance inflation factor) values for all independent variables were below 5 , indicating that there was no problem of multicollinearity (Besley et al., 1980).

\section{Multiple Regression Analysis with Moderator}

Multiple regression analysis was done to analyze the significant interaction between the dependent variable and the independent variables through the moderating variable.

Table 5 showed the relationship of workplace mindfulness on job performance was not conditioned by the age level. The result showed the interaction effect between workplace mindfulness and job performance $(\beta=0.037, p>0.05$.). Hence, age did not moderate the relationship between workplace mindfulness and job performance.
Table 5: Interaction between Dependent, Independent and Moderating Variable

\begin{tabular}{|l|c|c|c|c|}
\hline Interaction & $\begin{array}{l}\text { Standardized } \\
\text { beta }\end{array}$ & $\boldsymbol{t}$-value & $\boldsymbol{p}$-value & $\boldsymbol{R}^{\mathbf{2}}$ \\
\hline $\begin{array}{l}\text { Workplace Mindfulness + } \\
\text { Age + Job Performance }\end{array}$ & 0.037 & 0.160 & 0.873 & 0.080 \\
\hline $\begin{array}{l}\text { Cognition + Age + Job } \\
\text { Performance }\end{array}$ & 0.061 & 1.689 & $0.094 * *$ & 0.301 \\
\hline $\begin{array}{l}\text { Emotion + Age +Job } \\
\text { Performance }\end{array}$ & 0.058 & 0.655 & 0.514 & 0.205 \\
\hline $\begin{array}{l}\text { Behaviour + Age +Job } \\
\text { Performance }\end{array}$ & 0.062 & 2.911 & $0.004 *$ & 0.363 \\
\hline $\begin{array}{l}\text { Psychology + Age +Job } \\
\text { Performance }\end{array}$ & 0.056 & 2.169 & $0.032 *$ & 0.210 \\
\hline
\end{tabular}

Note: *-Significant at $p<0.05 ; * *_{-}$Significant at $p<0.1$

Besides that, the relationship of cognition on job performance was conditioned by the age level. The result showed the interaction effect between cognition and job performance $(\beta=0.061, p<0.1)$. Hence, age moderated positively and significantly the relationship between cognition and job performance. At a low level of age, the effect of cognition on job performance was weak, at a higher level of age, the effect of cognition on job performance was stronger.

The relationship of emotion on job performance was not conditioned by the age level. The result showed that the interaction effect between emotion and job performance $(\beta=0.058, p>0.05)$. Hence, age did not moderate the relationship between emotion and job performance.

The relationship of behaviour on job performance was conditioned by the age level. The result showed that the interaction effect between behaviour and job performance $(\beta=0.062, p<0.05)$. Hence, age moderated positively and significantly the relationship between behaviour and job performance. At a low level of age, the effect of behaviour on job performance was weak, at a higher level of age, the effect of behaviour on job performance was stronger. 
The relationship of psychology on job performance was conditioned by the age level. The result showed the interaction effect between psychology and job performance $(\beta=0.056, p<0.05)$. Hence, age moderated positively and significantly the relationship between psychology and job performance. At a low level of age, the effect of psychology on job performance was weak, at a higher level of age, the effect of psychology on job performance was stronger.

\section{DISCUSSION}

The objective of the study was to identify if workplace mindfulness, cognition, emotion, behaviour, and psychology impacted job performance and moderating role of age. This study aimed to enhance job performance among nurses in Malaysian government hospitals.

Based on the multiple regression results, ten hypotheses were tested where workplace mindfulness, cognition, and behaviour were found to have a positive significant influence on job performance and age moderated the relationship between cognition, behaviour, and psychology on job performance among nurses working in the Malaysian government hospitals.

Workplace mindfulness was found to have a positive significant influence on job performance among nurses working in Malaysian government hospitals, $(\beta=0.142, p<0.1)$. Therefore, hypothesis H1 was accepted. The results aligned with the researchers Dane \& Brummel, 2013; Reb, et al., 2015; Bea et al., 2018; Morgan et al., 2015; Good et al., 2016 who concluded in their studies that workplace mindfulness showed a significant positive impact on job performance. Nurses working in the Malaysian government hospitals have indicated that being mindful at work was necessary to contribute to job performance.

Based on the study done by Good et al., (2016), workplace mindfulness had four dimensions which were cognition, emotion, behaviour and psychology and these dimensions were proven to have had a positive significant impact on job performance. However, in this study the dimensions were measured individually; the results obtained from this research only proved that two variables which were cognition and behaviour, had a positive significant influence on job performance.
Cognition had a positive significant influence on job performance among nurses working in Malaysian government hospitals, $(\beta=0.355, p<0.05)$. The result was aligned with the study done by Good et al., (2016) where cognition had a positive significant impact on job performance. This also indicated that nurse's reactions, thoughts, and feelings in a certain situation were associated with their job performance. The ability to remain calm and have positive thoughts during difficult situations was vital for performing well. Hence, hypothesis $\mathrm{H} 2$ was accepted.

Emotion has a negative but no significant influence on job performance among nurses working in Malaysian government hospitals, $(\beta=-0.075, p>0.05)$. The result contradicted with the study done by Good et al., (2016) where emotion had a positive significant impact on job performance. The results indicated that nurses' emotional experience and emotional expressions did not affect their job performance. Hence, hypothesis H3 was not accepted.

Behaviour had a positive significant influence on job performance among nurses working in Malaysian government hospitals, $(\beta=0.399, p<0.05)$. The result was aligned with the study done by Good et al., (2016) where behaviour had a positive significant impact on job performance. Being responsible for the assigned duties and helping each other under the nursing community helped better job performance. An attitude that posed benefit to the organization and went a step ahead than their normal job scope significantly influenced job performance among nurses in the Malaysian government hospitals. Therefore, hypothesis H4 was accepted.

Psychology has a negative but not a significant influence on job performance among nurses working in Malaysian government hospitals, $(\beta=-0.012, p>0.05)$. The results contradicted with the study done by Good et $a l .$, (2016) where psychology had a positive significant impact on job performance because nurses were very much exposed to stressful situations and they were aware of the work stress which was why stress did not psychologically affect them in order to perform. Therefore, hypothesis $\mathrm{H} 5$ was rejected.

As for the moderating effect, age did not moderate the relationship of workplace mindfulness and job performance among nurses working in the Malaysian 
government hospitals, $(\beta=0.037, p>0.05)$. Therefore, hypothesis $\mathrm{H} 6$ was not supported.

Age moderated the relationship of cognition and job performance among nurses working in the Malaysian government hospital, $(\beta=0.061, p<0.1)$. Therefore, hypothesis $\mathrm{H} 7$ was supported. Age did not moderate the relationship of emotion and job performance among nurses working in the Malaysian government hospitals, $(\beta=0.058, p>0.05)$. Therefore, hypothesis $\mathrm{H} 8$ was not supported.

However, age moderated the relationship of behaviour and job performance among nurses working in the Malaysian government hospitals, $\beta=0.062$, $p<0.05)$. The results contradicted with the study done by Zacher (2015) and Griffin et al., (2016) where older workers had poor job performance compared to younger workers. This showed that the older the nurses were, the stronger their behaviour influenced job performance. Therefore, hypothesis H9 was supported.

Age also moderated the relationship between psychology and job performance among nurses working in the Malaysian government hospitals, $(\beta=0.056$, $p<0.05)$. The results contradicted with the study done by Zacher (2015) and Griffin et al., (2016) where older workers had poor job performance compared to younger workers. This showed that the older the nurses were, the stronger is their psychological influence on job performance. Therefore, hypothesis H10 was supported.

\section{Limitations}

Although the questionnaire was sent to over 150 government hospitals in Malaysia, the respondents could not cover all the hospitals as many did not respond. This was due to the restrictions set by the hospitals, where the staff was not allowed to participate in any survey of this nature. In addition, this study also could not cover all the nursing grades as the researcher was not allowed to have direct contact with the hospital staff. The variation within nursing grades in terms of responsibilities, job scope, and working environment could have some impact on the output of this study.

\section{RECOMMENDATIONS}

Future researchers should consider more ways to ensure all hospitals respond to the questionnaire through the recognition of the ministry of health and medical/nursing association. Besides that, future researchers should also consider studying each nursing grade individually to further understand its impact due to the variation in responsibility, job scope and working environment in each nursing grade.

\section{CONCLUSION}

The purpose of this study was to investigate the influence of workplace mindfulness, cognition, emotion, behaviour and psychology on job performance and if age moderated this relationship. It was found that only workplace mindfulness, cognition, and behaviour had a positive significant influence on job performance. Age moderated the relationship between cognition, behaviour, and psychology on job performance. Thus, the practitioner is suggested to focus on these three factors to enhance their strategies toward nurses working in Malaysian government hospitals.

\section{REFERENCES}

Andexer, C. (2016). Low wages driving Malaysian nurses away from the profession. CIMS Today. $13^{\text {th }}$ October. Retrieved from: https://today.mims.com/low-wages-driving-malaysian-nurses-away-from-the-profession

Augustin, R. (2017). No oversupply, high demand for Malaysian nurses. $7^{\text {th }}$ May. Free Malaysia Today. Retrieved from:https://www.freemalaysiatoday.com/category/nation/2017/05/07/no-oversupply-high-demand-formalaysian-nurses/

Bea, H., Chang, H. \& Eun, Y. (2018). The Mediating Effect of Mindfulness in the Relationship between SelfEsteem and Burnout among Clinical Nurses. Korean Journal of Stress Research, 26(3), pp 243-249.

Besley, D., Kuh, E. \& Welsch, R. (1980). Regression Diagnostics. Identifying Influential Data and Sources of 
Collinearity, Wiley Interscience, New York.

Dane, E. \& Brummel, B. J. (2013). Examining Workplace Mindfulness and Its Relations to Job Performance and Turnover Intention. Human Relations, 67(1), pp105-128.

Goh, J.M. (2017). Malaysia to face a nursing shortage by 2020. CIMS Today. $6^{\text {th }}$ January. Retrieved from: https://today.mims.com/malaysia-to-face-a-nursing-shortage-by-2020

Good, D.J., Lyddy, C.J., Glomb, T.M., Bono, J.E., Brown, K.W., Duffy, M.K., Baer, R.A., Brewer, J.A. \& Lazar. S.W. (2016). Contemplating Mindfulness at Work: An Integrative Review. Journal of Management, 42(1), pp 114-142.

Griffin, B., Bayl-Smith, P. \& Hesketh, B. (2016). The Longitudinal Effects of Perceived Age Discrimination on the Job Satisfaction and Work Withdrawal of Older Employees. Work, Aging and Retirement, 2(4), pp 415-427.

Ismail, N.S.N. (2017). A Diploma Dominated Service. $16^{\text {th }}$ January. Press Reader. Retrieved from: https://www.pressreader.com/malaysia/new-straits-times/20170116/281595240228202

Ling, S. (2015) Shortage of Nurses. $16^{\text {th }}$ May. The Star. Retrieved from: https:/www.thestar.com.my/metro/ community/2015/05/16/shortage-of-nurses-state-health-director-says-more-needed-to-improve-healthcareservice/

Morgan, P., Simpson, J. \& Smith, A. (2015). Health Care Workers' Experiences of Mindfulness Training: A Qualitative Review. Mindfulness, 6(4), pp 744-758.

Muthiah, W. (2017). Depression taking root within the workforce. The Star. $2^{\text {nd }}$ April. Retrieved from: https:/www.thestar.com.my/news/nation/2017/04/02/depression-taking-root-within-the-workforce-thisdisability-is-set-to-take-top-spot-in-affecting-pro/

Muthuveloo, R. \& Teoh, A.P. (2013). Achieving Business Sustainability Via I-Top Model. American Journal of Economics and Business Administration, 5(1), pp 15-21.

Muthuveloo, R. \& Teoh, A.P. (2014). Swim: Futuristic Framework For Strategic Management Process. American Journal of Applied Sciences, 11(9), pp 1703-1713.

Muthuveloo, R. \& Teoh, A.P. (2017). RACE: The Theory of Emergence for Strategic Entrepreneurship. International Review of Management and Marketing, 7(1), pp 164-168.

Reb, J., Narayanan, J. \& Ho, Z.W. (2015). Mindfulness at work: Antecedents and consequences of employee awareness and absent-mindedness. Mindfulness, 6(1), pp111-122.

World Health Organisation (2012). Malaysia health system review. Health Systems in Transition, 2(1). Geneva, Switzerland.

Zacher, H. (2015). Successful Aging at Work. Work, Aging and Retirement, 1(1), pp 4-25. 